\title{
Wetland Valuation Methods
}

\author{
Levent BİLER*, Ahmet ALTINDAĞ
}

Department of Biology, Faculty of Science, Ankara University, Ankara, TURKEY

ORCID ID: Levent BİLER: https:// orcid.org/0000-0002-2578-8530; Ahmet ALTINDAĞ: https://orcid.org/0000-0002-9900-5914

\begin{tabular}{|c|c|c|}
\hline Received: 30.03 .2020 & Published online: 04.06 .2020 & Issue published: 29.06 .2020 \\
\hline \multicolumn{3}{|c|}{$\begin{array}{l}\text { Abstract: Various methods are used in the valuation of the environment and especially wetlands. All of these methods are } \\
\text { summarized in this review paper and suggestions are discussed. Travel costs method in protected areas, the value of biological } \\
\text { diversity, contingent valuation method, and the value of the goods and services would be appropriate for valuation; even } \\
\text { though, Turkey has a flexible market. The value of biological diversity, the conditional valuation method, and the valuation } \\
\text { of goods and services with market value would be appropriate for unprotected areas and for the areas where visitors are not } \\
\text { logged. }\end{array}$} \\
\hline
\end{tabular}

Keywords: Travel cost method, contingent valuation method, market value, hedonic value, total economic value.

\section{Sulak Alan Kıymetlendirme Yöntemleri}

Öz: Çevrenin ve özellikle sulak alanların kıymetlendirilmesinde çeşitli yöntemler kullanılmaktadır. Bu yöntemler bu derleme makalesinde özetlenmiş ve öneri olarak sulak alanlarda hangi yöntemlerin uygulanabileceği tartışılmıştır. Korunan alanlarda seyahat masrafı yöntemi, biyolojik çeşitliliğin kıymeti, koşullu kıymetlendirme yöntemi ve her ne kadar Türkiye' de değişken bir piyasa olsa da piyasa kıymeti olan mal ve hizmetlerin kıymetlendirilmesi uygun olacaktır. Korunan alan dışındaki veya ziyaretçi kaydı tutulmadığı alanlarda biyolojik çeşitliliğin kıymeti, koşullu kıymetlendirme yöntemi ve piyasa kıymeti olan mal ve hizmetlerin kiymetlendirilmesi uygun olacaktır.

Anahtar kelimeler: Seyahat masrafı yöntemi, koşullu kıymetlendirme yöntemi, piyasa kıymeti, hedonik kıymetlendirme, toplam ekonomik kıymet.

\section{Giriş}

Tabiat-insan ilişkisi kendini dengeleyecek şekilde sürmektedir. Fakat kalkınma isteği nedeniyle denge tabiat aleyhine bozulmasına neden olmuştur. Özellikle 1972 yılındaki Birleşmiş Milletlerin Stockholm İnsan ve Çevre Konferansı'nda, doğal kaynaklara olan baskının artması ve kaynakların tükenmeye başlamasının maliyetinin çok yüksek olduğu dünya gündemine getirilmiştir. Böylece doğal kaynakların korunması ve sürdürülebilirliğinin sağlanması amaciyla çevresel kiymetlendirme yöntemlerinin kullanımı bir yol gösterici olarak kabul edilmiştir (Keleş \& Hamamc1, 1993).

Milyonlarca insana yarar ve hizmet sunan sulak alanların kıymeti 14 trilyon Amerikan Doları olarak tahmin edilmektedir (Barbier, Acreman, \& Knowler, 1997; Costanza et al., 1997). Sulak alanlar toprak yapisı nedeniyle tarımsal kullanım için zengin alanlar oluşturmaktadır. Bunun dışında gıda için balık, yakacak için odun, hasır için sazlık alanlar ve rekreasyon amaçlı alanlar sunmaktadır. Sulak alan çevresinde yaşayan yerel halk sulak alanları genellikle gıda, ilaç, kozmetik veya evleri için doğal malzeme kaynağı olarak kullanmaktadır (Adaya, Bdliya, Bitrus, \& Polet, 1997; Barbier et al., 1997). Ayrıca suyun kendisi de değerli bir maddedir. Taşkın önleme ve su arındırma gibi hizmetler, insanlara yarar sağlamaktadır. Sulak alanlar, kültürel mirasa veya onlarla ilişkili dini değerlerle bağlantılı olabilecek daha az maddi değere de sahiptir (Barbier et al., 1997).

Ekosistem işlev ve hizmetleri çeşitli ürünleri, hizmetleri ve nitelikleri kapsamakta olup, ekonomik üretime katkıda bulunan doğal sermayelerdir. Başlıca ürünler, balık ve sazlık gibi ekonomik değere sahip hasat edilen kaynaklardır. Buna ek olarak hizmetler, ekonomik artışa katkıda bulunan ya da su arıtımı gibi maliyetlerden tasarruf eden süreçlerdir. Nitelik; güzellik, nadirlik veya çeşitlilik gibi biyolojik çeşitliliğin yapısı ve organizasyonu ile ilgili olup, manevi, eğitsel, kültürel ve rekreasyonel değer gibi daha az somut değerler üretmektedir (Barbier, 1994).

Birleşmiş Milletler Çevre Programı́nın (UNEP) alt çalışma grubu olan Dünya Koruma ve İzleme Merkezi (World Conservation and Monitoring Center, WCMC), Asya ve gelişmekte olan Güney Amerika ülkelerinde sulak alanların tehdit altında olduğunu vurgulamıştır. Asya'daki sulak alanların \%32'sinin, Güney Amerika'daki sulak alanların ise \%30.5'inin aşırı avcılık faaliyetleri sonucu tehdit altında olduğu belirtilmiştir. Ayrıca Asya' da yerleşim yerlerinin, sulak alanların \%27'sini tehdit ettiği, su kirliliğinin ise Asya'da \%20, Güney Amerika'da \%31 tehdit unsuru olduğu vurgulanmıştır (Tiner, 1984).

Sulak alanlar; doğal ve insan tarafından gerçekleştirilen etkiye karşı savunmasız, duyarlı ekosistemlerdir (Turner et al., 2000). Sulak alanlar, korunmalarını sağlayan uluslararası ve ulusal mevzuatlara rağmen, giderek tehlike altına girmektedir (Bergstrom \& Stoll, 1993; Barbier et al., 1997; Turner et al., 2000). 1900 yılından bu yana birçok sulak alan tahrip edilmiş ve diğer arazi kullanımları için kurutulmuştur (Barbier, 1993). Türkiye'de sulak alanlar alternatif arazi kullanımlarına dönüştürülürken kurutulmakta, kirletilmekte, yabancı bitkiler tarafından istila edilmekte 
ve hidrolojik değişiklikler nedeniyle bozulmaktadır. Ayrıca geçmişte sıtma hastalığına karşı yürütülen mücadele sonucunda birçok sulak alan kurutulmuş ve kaybedilmiştir (Sönmez \& Somuncu, 2016; Biler, 2019).

Kiymetlendirme, dengeli karar verme açısından ekosistemin kazançlarının ve bozulma maliyetlerinin göstergesidir (Pearce, Whittington, Georgiou, \& Moran, 1994). Diğer bir deyişle, sulak alan kullanıcılarının sağladığı faydalar, kaybedilme maliyetleri ve sürdürülebilir arazi uygulamalarının kaynak edinme maliyetini belirlemek için bir temel oluşturmaktadır (Emerton, 1998).

Çevresel ekonomik kıymetlendirme, sulak alan tarafından sağlanan ürün ve hizmetlerin parasal değerini ortaya koyarak alan kapsamında optimal karar vermeyi kolaylaştırmakta ve çevreyi koruyan politikaları teşvik etmektedir (Batie \& Shabman, 1982; Helm, 1991).

Sulak alanların sağladığı faydaların daha iyi anlaşılmasının sonucu olarak, geçmişte tarım alanlarına dönüştürülen birçok sulak alan, şimdi yüksek maliyetler ile restore edilmektedir (Stuip, Baker, \& Oosterberg, 2002).
$\mathrm{Bu}$ derleme makalenin amacı mevcut kıymetlendirme yöntemlerini tartışarak sulak alanlarda uygulanabilecek yöntemleri önermektir.

\section{Sulak Alanların Kıymetlendirilmesi}

Ekonomik kıymetlendirme, ekosistemin sağladığı ürün ve hizmetlerin parasal değerini ortaya çıkararak alanları korumak için kullanılabilmektedir. Böylece alan ile ilgili en uygun kararı vermeyi kolaylaştırmakta ve çevre koruma politikalarına teşvik etmektedir (Batie \& Shabman, 1982; Helm, 1991).

Sulak alanların kıymetlendirilmesi amacıyla genel bir çerçeveye ihtiyaç duyulmaktadır. Bu çerçeve kullanıma en uygun olan toplam ekonomik kiymetlendirme kavramı (TEV)'dır (Pearce \& Warford, 1993). Sulak alanlara uygulanan toplam ekonomik kiymetlendirme çerçevesi Tablo 1'de özetlenmiştir.

Pazar değeri olan sulak alan ürünlerin hesaplanması kolay iken biyolojik çeşitlilik veya görsel peyzaj değerlerin hesaplanması oldukça zordur (Barbier et al., 1997; Turpie, Lannas, Scovronick, \& Louw, 2010).

Tablo 1. Sulak alanlar için toplam ekonomik kıymetin sınıflandırılması*

Table 1. Classification of total economic value for wetlands *

\begin{tabular}{llll}
\hline & \multicolumn{1}{c}{ Kullanım Değeri } & Kullanım Dışı Değerler \\
\hline Doğrudan Kullanım Kıymeti & Dolaylı Kullanım Kıymeti & Seçeneğe Bağlı Kıymet & \\
\hline Balık & Besin muhafaza etme & & \\
Tarım & Taşkın kontrolü & Potansiyel ileri vadede kullanım & \\
Yakacak odun & Firtına koruması & (doğrudan ve dolaylı kullanımlara & Bülojik çeşitlilik \\
Rekreasyon & Yeraltı suyu şarj ve deşarjı & göre) & Miras kıymeti \\
Ulaşım & Diş ekosistem desteği & Bilginin gelecekteki kıymeti & \\
Yaban hayatı & Mikro-klima stabilizasyonu & & \\
Turba / enerji & Kiyı stabilizasyonu, vd. & & \\
\hline
\end{tabular}

*Barbier (1989, 1993, 1994) ve Scodari (1990)'dan uyarlanmıştır.

Kiymetlendirme yöntemleri üç ana kategoriye ayrılmaktadır: piyasa değeri yaklaşımları, müşteri-pazar yaklaşımları ve temsili pazar yaklaşımları. Müşteri pazar ve temsili pazar yaklaşımlarında sulak alan için (korumak, rekreasyonel olarak kullanmak, vs.) kullanıcıların ödeme arzuları ile kıymetlendirme gerçekleşirken, piyasa değeri yaklaşımlarda tamamen piyasa fiyatlarına dayanmaktadır (Perrings, Maler, Folke, Holling, \& Jansson, 1997). Çevresel mal ve hizmetlerin toplam ekonomik kıymeti; piyasa değeri yaklaşımları, temsili pazar ve simüle edilmiş pazar şeklinde siniflandırılmaktadır (Turner, Morse-Jones, \& Fisher, 2010).

\subsection{Piyasa Değeri Yaklaşımları}

$\mathrm{Bu}$ yaklaşıma göre doğal sistemlerin hem doğrudan hem de dolaylı kullanimı kiymetlendirilmektedir. Bu kapsamda herhangi bir üretim girdisi; turizm, mühendislik süreçleri gibi durumlarda doğrudan veya dolaylı kullanım kıymetlendirilmesi uygulanabilmektedir (Turpie et al., 2010).

Piyasa kiymetlendirmesi: Piyasa kıymetlendirilmesi kapsamında piyasada alınıp satılan mal veya hizmetler standart ekonomik yöntemler ile hesaplanmaktadır (Turpie et al., 2010).

Piyasa fiyatlarının mevcut olduğu yerlerde hasat edilen kaynaklar bu kapsamda kiymetlendirilmektedir (Barbier et al., 1997; Batie \& Shabman, 1982). Fiyatlar genellikle bakanlıkça belirlenen ya da "üretici fiyatı" seviyesinde yapılmaktadır. Bu kapsamda bir sulak alanın tam kıymeti, nihai tüketici veya ihracat noktasına kadar almak daha uygun olacaktır (Turpie et al., 2010). Eğer kaynaklar için market fiyatları mevcut değil ise, vekil fiyatlar kullanılabilir (Barbier et al., 1997).

Üretim fonksiyonu yaklașımı: Bu yaklaşım, mal (hizmet) ile çevrenin durumu arasındaki ilişkinin veya sulak alan kaynağındaki değişikliklerin üretimi üzerindeki fiziksel etkilerin dinamik fonksiyonlar dikkate alınarak modellenmesi ile ölçülmektedir. Bu yöntem zaman serileri veya kesitsel analizlerle gerçekleştirilir ve bu nedenle genellikle birkaç y1ldan uzun süren veri veya birkaç bölgeden karşılaştırılabilir veriyi gerektirir (Turpie et al., 2010).

Restorasyon maliyeti veya yenileme maliyeti yöntemleri: $\mathrm{Bu}$ yöntem, ekosistemin sağladığı faydaların veya hizmetlerin restore edilmesini (örneğin: habitat restorasyonu) veya bunların yapay ikamelerle değiştirmenin maliyetini baz alır (Turpie et al., 2010).

Koruma maliyet yöntemi: Bu yöntem “onarım” maliyetleri yerine, önleme maliyetlerine odaklanmaktadır. Bu yönteme göre sulak alanın bozulması veya elde edilen faydanın kaybedilmesi durumunda zararın önlenmesi için ortaya çıkan maliyeti baz alır. Örneğin, sulak alanın taşkın koruma özelliğinin yitirilmesi sonucu inşaatı yapılacak olan bentlerin maliyeti koruma maliyeti olarak değerlendirilmektedir (Turpie et al., 2010). 


\subsection{Temsili pazar / belirtilen tercih yaklaşımları}

Temsili Pazar / belirtilen tercih yaklaşımları, seyahat maliyeti yöntemi ve hedonik k1ymetlendirme yöntemini kapsamaktadır (Turpie et al., 2010).

Seyahat maliyet yöntemi (Travel Cost Method = TCM): Bu yöntem, ziyaretçilerin bir alanı kullanmak için ödedikleri zaman ve yaptıkları masrafları içermektedir. Bu şekilde tüketicinin arzını hesaplanabileceği bir talep eğrisi oluşturulmaktadır. Tüketici arzı, insanların alanı kullanmak için ödemeye razı olacakları ilave ödemek zorunda kalacakları tutarı yansıtmaktadır (Turpie et al., 2010).

Bir seyahat maliyeti tahmini için veri oldukça önemlidir ve anket uygulamalarını içerir. Veriler, sahaya gelen ziyaretçi sayısını, kökenlerini, sosyo-ekonomik özelliklerini, sahadaki yolculuk süresini ve harcanan zamanı, doğrudan seyahat harcamalarını ve diğer seyahatlerin amaçlarını içerir. Alanı ziyaret etmenin maliyeti, harcanan zamanın maliyetini de içermektedir (Smith, Desvouges, \& McGivney, 1983; Shaw, 1992).

Hedonik kıymetlendirme yöntemi (Hedonic Pricing $=H P$ ): Alanda bulunan arsaların fiyatlarının modellenmesi yoluyla alanlarin kiymetlerinin hesaplanması mümkündür (Perman, Ma, \& McGilvray, 1996). Bu yöntem, gecekondu bölgeleri gibi mülk piyasasının olmadığı veya mülk pazarlarının çarpık olduğu yerlerde uygun değildir. Kaynakların sinırlı olduğu yerlerde, emlakçı görüşmeleri yoluyla makul tahminler elde etmek de mümkündür (Van Zyl, \& Leiman, 2002).

Hedonik fiyat yöntemi, pek çok ülkede kamuoyuna bilgi sağlaması açısından önemini korumaktadır (Kula, 1994).

\subsection{Simüle edilmiş pazar / belirtilen tercihli yaklaşımlar}

Simüle edilmiş piyasa (veya "belirtilen tercih") yöntemleri, seçenek ve kullanım dişı değerleri tahmin etmek için bir yol sunar ve rekreasyonel kullanım kıymetinin ölçülmesinde de sıklıkla kullanılır (Turpie et al., 2010).

Koșullu kıymetlendirme yöntemi (Contingent Valuation Method = CVM): Koşullu kıymetlendirme yöntemi, anket yoluyla insanların doğal kaynaklara erişim ve doğal kaynakların varlığı için ödeme istekliliklerini (Willingness-to-pay, WTP) kiymetlendirmektedir (Mitchell \& Carson, 1989). Ödeme istekliliği, alan kullanıcıların biyolojik çeşitliliği korumak için ödemeyi kabul ettikleri miktarı temsil etmektedir. Anket yoluyla katılımcılara biyoçeşitliliğin korunması için ödeme isteklilikleri bir dizi soru sorularak ortaya konmaktadır. Ödeme istekliliği, açı uçlu sorular, referandum veya iki seçenekli seçim (evet-hayır) tipi sorular, ihale oyunları, takas oyunları, sıralama teknikleri, masrafsız seçim seçenekleri veya öncelikli değerlendirme tekniği ile ortaya çıkabilmektedir (Turpie et al., 2010).

Birleşik değerleme yöntemleri (seçim modellemesi; koşullu sıralama): Seçim modellemesi veya koşullu sıralama yöntemi pazarlama alanında geliştirilmiş ve sulak alanlar dahil çevresel kaynakların kiymetlendirilmesinde uygulanmaktadır (Green \& Rao, 1971; Stevens, Belkener, Dennis, Kittredge, \& Willis, 2000; Turpie \& Joubert, 2001; Johnston, Grigalunas, Opaluch, Mazzotta, \& Diamantedes,
2002; Carlsson, Frykblom, \& Liljenstolpe, 2003; Hanley, Wright, \& Alvarez-Farizo, 2006; Birol, Karousakis, \& Koundouri, 2006). Bu yöntem, bir hizmetin farklı bileşenlerinin genel kıymete nasıl katkıda bulunduğunu ve belirli özellikler değiştiğinde bu genel kıymetin nasıl değiştiğini tespit etmeye çalışmaktadır (Turpie et al., 2010).

Fayda transferi yöntemi: Bir hizmetin veya malın belirli alandaki kıymetinin hesaplanamaması durumunda farklı alanlardaki aynı hizmet veya mal kıymetini söz konusu alana uygulamak mümkün olabilir (Georgiou, Whittington, Pearce, \& Moran, 1997; Barbier et al., 1997). $\mathrm{Bu}$ yöntemle ekonomik kıymet mevcut veya düzeltilmiş tahmininin, söz konusu mal veya hizmetin ekonomik kıymetini tahmini olarak kullanılabileceği varsayılmaktadır (Turpie et al., 2010).

\section{Sonuç ve Öneriler}

Dünya, aşırı nüfus artışı, kentleşme, sanayileşme ve aşırı kaynak kullanımından dolayı tehdit altındadır. Su kaynakları da bu nedenle gün geçtikçe kirlenmektedir.

Türkiye'de sulak alanlar ile ilgili kanun ve yönetmeliklerde eksiklikler bulunmaktadır. Özellikle sulak alanlar üzerindeki yetki karmaşası en önde gelmektedir. Bazı sulak alanların birden fazla statüye sahip olması alan üzerindeki yetki karmaşasını ortaya çıkarmaktadır. Ayrıca kanun ve yönetmeliklerin 1950'li yıllarda oluşturulmuş olması sulak alanların korunması ve yönetilmesinde sıkıntılar yaşanmasına neden olmaktadır.

Ramsar prensiplerinin uygulanabilmesi amaciyla "Sulak Alanların Korunması Yönetmeliği" belirli stratejiler içermektedir. Bu yönetmelik kapsamında kurulan komisyon "2003-2008 Ulusal Sulak Alan Stratejisini" hazırlamış ve sulak alanların daha iyi yönetilmesini hedeflemiştir. Ramsar Anlaşması ve Ulusal Sulak Alan Stratejisi, sulak alanların kıymetlendirilmesinin önemini vurgulamaktadır.

Bazı kıymetlendirme yöntemleri, belirli ekosistem hizmetlerini değerlendirmek ve belirli kıymet bileşenlerini ortaya çıkarmak için diğerlerinden daha uygundur. Tablo 2 'de belirli yöntemler ve kıymet bileşenleri arasındaki bağlantıları gösterilmektedir.

Barbier et al. (1997) tarafından oluşturulmuş sulak alanlara yönelik kıymetlendirme yöntemlerinin avantaj ve dezavantajları Tablo 3' de özetlenmiştir.

Türkiye' de sulak alan kıymetlendirilmesi konusunda çok az çalışma bulunmaktadır. Çalışmalara ait bilgi ve sonuçlar aşağıda yer almaktadır.

Ortaçeşme, Özkan, ve Karagüzel (2002) tarafından gerçekleştirilen "Kurşunlu Şelalesi Tabiat Parkı'nın Ekonomik Değerinin Saptanması" konulu makalede seyahat maliyeti yöntemi uygulanmış ve parkın yıllık tüketici fazlalığ1 50 milyar TL olarak tahmin edilmiştir. Başar (2007) çalışmasında Dilek Yarımadası Büyük Menderes Deltası Milli Parkı'nın rekreasyonel kullanım değerini belirlemek amaciyla seyahat maliyeti yöntemi sonucunda 41.990.000 TL kıymet elde etmiştir. Gürlük ve Rehber (2008) seyahat maliyeti yöntemi ile Manyas Gölü Kuş Cenneti Milli Parkı'nın kuş gözlemciliği faaliyetlerini kıymetlendirerek yıllık hane başına 1.614.376 ABD doları gelir elde ettiğini rapor etmişlerdir. 
Pak ve Türker (2004), koşullu kıymetlendirme yöntemi ile Kapıçam Orman İçi Dinlenme Yeri'nin kıymetini 22.042.500.000 TL olarak hesaplamışlardır. Gürlük (2006) Manyas Gölü'nde koşullu kıymetlendirme yöntemiyle ekosistem ve rekreasyon değerlerini toplam
14.809.183,74 TL/yıl olarak hesaplamıştır. Gürlük (2010) Uluabat Gölü'nde koşullu kıymetlendirme yöntemini uygulayarak ortalama ve medyan değerlerine göre sirasiyla 4.848.000,00 ila 8.100.000,00 ABD Dolar1/y1l kıymet hesaplamıştır.

Tablo 2. Kıymetlendirme yöntemleri ve kıymet türleri arasındaki ilişki*

Table 2. The relationship between valuation methods and value types *

\begin{tabular}{llll}
\hline \multicolumn{1}{c}{ Yaklaşım } & & \multicolumn{1}{c}{ Yöntem } & Kıymet / Değer \\
\hline \multirow{3}{*}{ Piyasa kıymetlendirmesi } & Fiyat bazlı & Piyasa değeri yaklaşımları & Doğrudan ve dolaylı kullanım \\
\cline { 2 - 4 } & \multirow{2}{*}{ Ücret bazlı } & $\begin{array}{l}\text { Koruma maliyeti yöntemi } \\
\text { Azaltma / Restorasyon maliyeti }\end{array}$ & $\begin{array}{l}\text { Doğrudan ve dolaylı kullanım } \\
\text { Doğrudan ve dolaylı kullanım }\end{array}$ \\
\cline { 2 - 4 } & Üretim bazlı & Üretim fonksiyonu yaklaşımı & Dolaylı kullanım \\
\hline \multirow{2}{*}{ Açılanmı̧ tercih } & Seyahat maliyeti yöntemi & Doğrudan (dolaylı) kullanım \\
& & Hedonik kıymetlendirme & Doğrudan ve dolaylı kullanım \\
\hline \multirow{2}{*}{ Belirtilen tercih } & Koşullu kıymetlendirme & Kullanım ve kullanım dışı \\
& & Seçim modellemesi / Birleşik analiz & Kullanım ve kullanım dışı \\
& Fayda transferi yöntemi & Kullanım ve kullanım dışı
\end{tabular}

* Fisher \& Christie (2010)'den uyarlanmıştır.

Tablo 3. Sulak alan kıymetlendirme tekniklerinin avantaj ve dezavantajları*

Table 3. Advantages and disadvantages of wetland valuation techniques *

\begin{tabular}{|c|c|c|}
\hline Kıymetlendirme Tekniği & Avantaj1 & Dezavantajı \\
\hline $\begin{array}{l}\text { Piyasa değeri yaklaşımları } \\
\text { Mallar için geçerli fiyatlar kullanılır ve iç } \\
\text { veya dış pazarlarda işlem gören hizmetler } \\
\text { ele alınır. }\end{array}$ & $\begin{array}{l}\text { Piyasa fiyatları sulak alanda ticari faydaları } \\
\text { (örneğin, balık, kereste, yakacak odun, } \\
\text { rekreasyon vb.) yansıtır. Bunlar finansal veri } \\
\text { oluşturmak için kullanılabilir Fiyat verileri elde } \\
\text { edilmesi nispeten kolaydır. }\end{array}$ & $\begin{array}{l}\text { Piyasa çalkalanmaları ve/veya politikalardaki } \\
\text { başarısızlıklar mal veya hizmetlerin piyasadaki } \\
\text { fiyatlarında değişikliğe neden olabilirler. Ayrıa } \\
\text { mevsimsel de piyasadaki fiyatları etkileyebilir. }\end{array}$ \\
\hline $\begin{array}{l}\text { Hedonik kıymetlendirme } \\
\text { Çevresel bir konforun mülk piyasalarından } \\
\text { elde edilir. Temel varsayım, gözlenen mülk } \\
\text { değerinin bir fayda yansıttığı ve ilgili } \\
\text { çevresel özellik veya niteliğin değerini } \\
\text { ortaya koyduğudur. }\end{array}$ & $\begin{array}{l}\text { Hedonik kıymetlendirme, sulak alan işlevlerinin } \\
\text { arazi fiyatlarına tam olarak yansıtıldığı } \\
\text { varsayılarak, belirli sulak alan fonksiyonlarının } \\
\text { (örneğin, fırtına koruması, yeraltı suyu şarjı) } \\
\text { arazi değerleri üzerindeki etkileri açısından } \\
\text { değerleme potansiyeline sahiptir. }\end{array}$ & $\begin{array}{l}\text { Hedonik kıymetlendirmenin sulak alanların çevrese } \\
\text { işlevlerine uygulanması, bu değerlerin vekil piyasalara } \\
\text { yansıtılmasını gerektirir. Piyasalar çarpıtılmış, seçimler } \\
\text { gelirle kısıtlanmış, çevre koşulları hakkında bilgi yaygın } \\
\text { olmadığı ve veriler az olduğunda yaklaşım sınırl } \\
\text { olabilmektedir. }\end{array}$ \\
\hline $\begin{array}{l}\text { Seyahat maliyeti yaklaşımı } \\
\text { Seyahat maliyeti yaklaşımı, insanların } \\
\text { bölgeyi ziyaret etmek için harcadıkları para } \\
\text { miktarı ve zamanı hakkında bilgi } \\
\text { kullanarak belirli bir konumdaki çevresel } \\
\text { faydalar için ödeme yapma istekliliğini } \\
\text { ölçer. }\end{array}$ & $\begin{array}{l}\text { Gelişmiş ülkelerdeki kamu parkları ve vahşi } \\
\text { yaşam rezervleri dahil olmak üzere rekreasyon } \\
\text { alanlarının değerini tahmin etmek için yaygın } \\
\text { olarak kullanılır. Bazı gelişmekte olan ülkelerde } \\
\text { tropikal sulak alanlara eko-turizm için ödeme } \\
\text { yapma istekliliğini tahmin etmek için } \\
\text { kullanılabilir. }\end{array}$ & $\begin{array}{l}\text { Veri yoğunluğu ve tüketici davranışı ile ilgili yanıltıc } \\
\text { (örneğin; aynı anda birden çok alan ziyareti) olaylar talep } \\
\text { ilişkisini belirlemek için kullanılan istatistiksel } \\
\text { yöntemlere son derece duyarlıdır. }\end{array}$ \\
\hline $\begin{array}{l}\text { Üretim fonksiyonu yaklaşımı } \\
\text { Kaynak veya işlevin ekonomik çıtıya } \\
\text { fiziksel katkısını modelleyerek, } \\
\text { pazarlanmamış bir kaynağın veya ekolojik } \\
\text { işlevin ekonomik faaliyetteki değişiklikler } \\
\text { açısından değerini tahmin eder. }\end{array}$ & $\begin{array}{l}\text { Sulak alanların ve resif bozulmaların, } \\
\text { ormansızlaşma ve su kirliliğinin gibi etkenleri ve } \\
\text { balıkçılık, avcılık ve tarım gibi üretken } \\
\text { faaliyetlerin kıymetini tahmin etmek için yaygın } \\
\text { olarak kullanılabilmektedir. }\end{array}$ & $\begin{array}{l}\text { Değerlenen kaynak veya işlev ile bazı ekonomik çıtıtır } \\
\text { arasındaki 'doz-yanıt' ilişkisinin açıkça modellenmesini } \\
\text { gerektirir. Yaklaşımın uygulanması, tek kullanımlık } \\
\text { sistemler söz konusu olduğunda basittir, ancak çoklu } \\
\text { kullanım sistemleriyle daha karmaşı hale gelmektedir. } \\
\text { Ekoloji-ekonomi ilişkisinin çoklu seçim veya çift } \\
\text { sayımdan kaynaklanan sorunlar ortaya çkabilmektedir. }\end{array}$ \\
\hline $\begin{array}{l}\text { Yapılandırılmış pazar teknikleri } \\
\text { Doğrudan tüketici tercihlerini belirterek } \\
\text { ödeme istekliliğinin ölçülmesidir. } \\
\text { Simüle edilmiş piyasa (SM), gerçekte el } \\
\text { değiştirdiği deneysel bir pazar inşa eder. } \\
\text { Koşullu değerleme yöntemi (CVM), } \\
\text { katılımcıların ödeme istekliliğini sağlamak } \\
\text { için varsayımsal bir pazar inşa eder. }\end{array}$ & $\begin{array}{l}\text { Hicksian'ın refah ölçüsünü doğrudan tahmin } \\
\text { eder-ödeme istekliliğinin en iyi teorik ölçümünü } \\
\text { sağlar. } \\
\text { SM: Kontrollü deneysel ortam, tercihleri } \\
\text { belirleyen faktörlerin yakından incelenmesini } \\
\text { sağlar. } \\
\text { CVM: sadece opsiyon ve varlık değerlerini } \\
\text { ölçebilen ve toplam ekonomik değerin gerçek bir } \\
\text { ölçüsünü sağlayan yöntemdir. }\end{array}$ & $\begin{array}{l}\text { Yapılandırılmış pazar tekniklerinin pratik kısıtlamaları } \\
\text { teorik avantajlardan uzaklaşarak gerçek ödeme } \\
\text { istekliliğinin düşük olmasına yol açabilir. } \\
\text { SM: Gelişmiş tasarım ve uygulama, gelişmekte olan } \\
\text { ülkelerde uygulamayı sınırlandırabilir. } \\
\text { CVM: anket tasarımı ve uygulamasında çok sayıda } \\
\text { önyargı sonuçları etkiler. }\end{array}$ \\
\hline $\begin{array}{l}\text { Maliyete dayalı kıymetlendirme } \\
\text { Çevresel fayda kıymetinin tahmini olduğu } \\
\text { varsayımına dayanmaktadır. Ödeme } \\
\text { istekliliğini tahmin etmek için: } \\
\text { Restorasyon maliyeti yöntemi, ekosistem } \\
\text { mallarını veya hizmetlerini geri yükleme } \\
\text { maliyetlerini kullanır. }\end{array}$ & 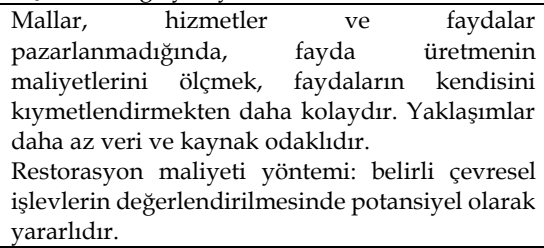 & $\begin{array}{l}\text { Bu yaklaşımlar, harcamanın pozitif faydalar sağladığını } \\
\text { ve harcamalardan kaynaklanan net faydaların orijinal } \\
\text { fayda seviyesine uygun olduğunu varsayar. Bu koşullar } \\
\text { yerine getirildiğinde bile, maliyetler genellikle faydaların } \\
\text { doğru bir ölçüsü olmayabilir. } \\
\text { Restorasyon maliyeti yöntemi: azalan getiri ve önceki } \\
\text { ekosistem koşullarını geri yükleme zorluğu restorasyon } \\
\text { maliyeti yöntemi uygulamasını tartışmalı hale getiriyor. }\end{array}$ \\
\hline
\end{tabular}

* Barbier et al. 1997'dan uyarlanmıştır.

Mülga T.C. Orman ve Su İşleri Bakanlığı (2012) tarafından hazırlanan raporda Sultan Sazlığı Milli Parkı'nın toplam kıymetinin 1.447.996.364,87 TL olduğunu beyan etmiştir. Bu kapsamda doğrudan kullanılan ve piyasa değeri bulunan mal ve hizmetler kapsaminda alanlardaki hayvansal üretim (süt üretimi ve et üretimi), bitkisel üretim, mera ot üretimi, gübre üretimi, biyoyakıt üretimi, kullanılan su miktarı, biyolojik çeşitlilik ve organik madde kıymeti yapılmıştır.

Biler (2019) Balıkdamı Sulak Alanı kıymetlendirme çalışmasında sulak alanın 23.820.342,93 TL olduğunu rapor etmiştir. Bu çalışmada koşullu kıymetlendirme yöntemi ile doğrudan kullanılan ve piyasa değeri bulunan mal ve hizmetler kapsaminda alanlardaki hayvansal üretim (süt üretimi ve et üretimi), bitkisel üretim, mera ot üretimi, gübre üretimi, biyoyakıt üretimi, kullanılan su 
miktarı, biyolojik çeşitlilik ve organik madde kıymeti yapılmıştır.

Yapılacak olan kıymetlendirme çalışmalarında sulak alanin korunan alan olup olmaması önem arz etmemektedir. Korunan alanlarda alanlara giriş ve çıkışların kaydı alındığı için, seyahat masrafı yöntemi, biyolojik çeşitliliğin kıymeti, koşullu kıymetlendirme yöntemi ve her ne kadar Türkiye'de değişken bir piyasa olsa da piyasa kiymeti olan mal ve hizmetlerin kıymetlendirilmesi uygun olacaktır. Korunan alan dışındaki veya ziyaretçi kaydı tutulmadığı alanlarda biyolojik çeşitliliğin kıymeti, koşullu kıymetlendirme yöntemi ve piyasa kıymeti olan mal ve hizmetlerin kiymetlendirilmesi uygun olacaktır (Biler, 2019).

\section{Öneriler}

- Sulak Alan çevresinde yaşayan yerel halk, sulak alanın korunmasında yer almalıdır. Yerel halk kilit paydaş olarak katılımı teşvik edilmelidir.

- Yerel halkın biyoloji ve sulak alan konusundaki bilgileri pekiştirilmeli ve ne kadar kıymetli bir alanda yaşadıkları tanıtılmalıdır.

- Yerel halkın sulak alandan nasıl fayda sağlayabileceği tanitilmalidir.

- Sulak alanın kıymeti ekonomik politikalara ve kalkınma planlarına yansitılmalıdır. Hükümet kararları, sulak alanın ekonomik faydalarını ve kaybının ekonomik maliyetlerini göz önünde bulundurmalıdır.

\section{Kaynaklar}

Adaya, A.L., Bdliya, H.H., Bitrus, H., \& Polet, G. (1997). Local-level assessment of the economic importance of wild resources in the Hadejia-Nguru Wetlands, Nigeria (Sustainable Agriculture Programme Research Series, vol. 3). Report compiled by the participants and resource people in the IIED/HNWCP Hidden Harvest case study.

Barbier, E., Acreman, M.C., \& Knowler, D. (1997). Economic Valuation of Wetlands: A Guide for Policy Makers and Planners. Department of Environmental Economics and Environmental Management, University of York Institute of Hydrology, Ramsar Convention Bureau, Switzerland, $127 \mathrm{pp}$.

Barbier, E.B. (1989). The Economic Value of Ecosystems:1 - Tropical Wetlands. Issue 89, Part 2 of Gatekeeper series / LEEC, London, The United Kingdom, International Institute for Environment and Development, 18 pp.

Barbier, E.B. (1993). Sustainable use of wetlands - valuing tropical wetland benefits: Economic methodologies and applications. The Geographical Journal, 159, 22-32. http://dx.doi.org \10.2307/3451486

Barbier, E.B. (1994). Valuing environmental functions: Tropical wetlands. Land Economics, 70, 155-173. http://dx.doi.org \10.2307/3146319

Başar, H. (2007). Dilek Yarımadası-Büyük Menderes Deltası Milli Parkının Rekreasyon Amactyla Kullanımının Ekonomik Değerinin Saptanması: Bir Seyahat Maliyeti Yöntemi Uygulaması (Yüksek Lisans Tezi). Ege Üniversitesi, İzmir, Türkiye.

Batie, S.S., \& Shabman, L.A. (1982). Estimating the economic value of wetlands: Principles, methods and limitations. Coastal Zone Management Journal, 10, 255-278. https:// doi.org/10.1080/08920758209361920

Bergstrom, J.C., \& Stoll, J.R. (1993). Value estimator models for wetlandsbased recreational use values. Land Economics, 69(2), 132-137. https://doi.org/10.2307/3146513

Biler, L. (2019). Sulak Alanlar, Değer Biçme ve Türkiye'ye Özgü Yöntem Belirlenmesi ve Balıkdamı Sulak Alanında Uygulanması (Doktora Tezi). Ankara Üniversitesi, Ankara, Türkiye.

Birol, E., Karousakis, K., \& Koundouri, P. (2006). Using a choice experiment to account for preference heterogeneity in wetland attributes: The case of Cheimaditida wetland in Greece. Ecological Economics, 60(1), 145-156. https://doi.org/10.1016/j.ecolecon.2006.06.002
Carlsson, F., Frykblom, P., \& Liljenstolpe, C. (2003). Valuing wetland attributes: An application of choice experiments. Ecological Economics, 47(1), 95-103. https://doi.org/10.1016/j.ecolecon.2002.09.003

Costanza, R., d'Arge, R., De Groot, R., Farber, S., Grasso, M., Hannon, B., Limburg, K., Naeem, S., O'Neill, R.V., Paruelo, J., Raskin, R.G., Sutton, P., \& van den Belt, M. (1997). The value of the world's ecosystem services and natural capital. Nature, 387, 253-259. https://doi.org/10.1038/387253a0

Emerton, L. (1998). Economic Tools for Valuing Wetlands in Eastern Africa. Nairobi, Kenya, IUCN - The World Conservation Union, 21 pp.

Fisher, B., \& Christie, M. (2010). The Economics of Ecosystems and Biodiversity: The Ecological and Economic Foundations. In R. De Groot, B. Fisher, M. Christie, J. Aranson, L. Braat, R. Haines-Young, E. Maltby, A. Neuville, S. Polasky, R. Portela \& I. Ring (Eds.), Integrating the ecological and economic dimensions in biodiversity and ecosystem service valuation (pp. 3-33). London and Washington, The UK and The USA, Pushpam Kumar, 422 pp.

Georgiou, S., Whittington, D., Pearce, D., \& Moran, D. (1997). Economic Values and the Environment in the Developing World. London, The United Kingdom, Edward Elgar Publishing Limited, 171 pp.

Green, P.E., \& Rao, V.R. (1971). Conjoint measurement for quantifying judgement data. Journal of Market Research, 8, 355-363. https://doi.org/10.1177/002224377100800312

Gürlük, S. (2006). Manyas Gölü ve Kus Cenneti'nin Cevresel Değerlemesi Üzerine Bir Araştırma (Doktora Tezi). Uludağ Üniversitesi, Bursa, Türkiye.

Gürlük, S. (2010). Economic Value of an Environmental Management Plan: Case of Uluabat Lake. Journal of Biological and Environmental Sciences, 4(11), 59-65.

Gürlük, S., Rehber, E. (2008). A travel cost study to estimated recreational value for a bird refuge at Lake Manyas, Turkey. Journal of Environmental Management, 88(4), 1350-1360. https://doi.org/10.1016/j.jenvman. $\underline{2007.07 .017}$

Hanley, N., Wright, R.E., \& Alvarez-Farizo, B. (2006). Estimating the economic value of improvements in river ecology using choice experiments: An application to the water framework directive. Journal of Environmental Management, 78(2), 183-193. https://doi.org/10.1016/ j.jenvman.2005.05.001

Helm, D. (1991). Economic Policy Towards the Environment. Blackwell Publication, $326 \mathrm{pp}$.

Johnston, R.J., Grigalunas, T.A., Opaluch, J.J., Mazzotta, M., \& Diamantedes, J. (2002). Valuing estuarine resource services using economic and ecological models: The Peonic Estuary System study. Coastal Management, 30(1), 47-65. https://doi.org/10.1080/ $\underline{08920750252692616}$

Keleş, R., \& Hamamcı, C. (1993). Çevrebilim. Ankara, Türkiye, İmge Kitabevi, 368 pp.

Kula, E. (1994). Economics of natural resources, the environment and policies. London, UK, $377 \mathrm{pp}$

Mitchell, R.C., \& Carson, T.R. (1989). Using surveys to value public goods: The contingent valuation method. Washington D.C., The United States of America, Resources for the Future, 463 pp.

Ortaçeşme, V., Özkan, B., \& Karagüzel, O. (2002). An estimation of the recreational use value of Kursunlu Waterfall Nature Park by the individual travel cost method. Turkish Journal of Agriculture and Forestry, 26(1), 57-62.

OSİB. (2012). Biyokıymetlendirme Teknik Uygulayıcıları: Sultan Sazlığı Milli Parkı Pilot Uygulaması (T.C. Orman ve Su İşleri Bakanlığı). Ankara, Türkiye, Taha Grup Kırtasiye, 456 pp.

Pak, M., \& Türker, M.F. (2004). Orman Kaynağından Rekreasyonel Amaçlı Yararlanmanın Ekonomik Değerinin Koşullu Değerlendirme Yöntemi Yardımıyla Tahmin Edilmesi (Kapıçam Orman İçi Dinlenme Yeri Örneği). Kahramanmaraş Sütçü İmam University Journal of Science and Engineering, 7(1), 59-65.

Pearce, D., Whittington, D., Georgiou, S., \& Moran, D. (1994). Economic values and the environment in the developing World. London, The United Kingdom, Edward Elgar Publishing Limited, 171 pp.

Pearce, D.W., \& Warford, J.J. (1993). World Without End. Washington D.C., The United States of America, Oxford University Press, 440 pp.

Perman, R., Ma, Y., \& McGilvray, J. (1996). Natural Resource and Environmental Economics. London, UK, Longman Group Limited, 396 pp.

Perrings, C., Maler, K.G., Folke, C., Holling, C.S., \& Jansson B.O. (1997). Biodiversity Loss: Economic and Ecological Issues. In Turner, R.K., Folke, C., Gren, I. M., \& Bateman, J. I. (First Edition), Wetland Valuation: 
Three case Studies (pp. 129-149). Cambridge, the UK, Cambridge University Press, 332 pp.

Scodari, P.F. (1990). Wetlands Protection: the Role of Economics. Washington, D.C., The USA, Environmental Law Institute, 89 pp.

Shaw, W.D. (1992). Searching for the opportunity cost of an individual's time. Land Economics, 68(1), 107-115. https://doi.org/10.2307/3146747

Smith, V.K., Desvouges, W.H., \& McGivney, M.P. (1983). The opportunity cost of travel time in recreation demand models. Land Economics, 59 (3), 259-278. https://doi.org/10.2307/3145728

Sönmez, M.E. \& Somuncu, M. (2016). Sultansazlığı'nın alansal değişiminin sürdürülebilirlik açısından değerlendirilmesi. Türk Coğrafya Dergisi, 66, 1-10. https://doi.org/10.17211/tcd.70341.

Stevens, T.H., Belkener, R., Dennis, D., Kittredge, D., \& Willis, C. (2000). Comparison of contingent valuation and conjoint analysis in ecosystem $\begin{array}{llll}\text { management. Ecological Economics, 32(1), 63-74. } & \end{array}$ https://doi.org/10.1016/S0921-8009(99)00071-3

Stuip, M.A.M., Baker, C.J., \& Oosterberg, W. (2002). The Socio-economics of Wetlands. Wageningen, the Netherlands, Wetlands International and RIZA, 34 pp.

Tiner, R.W. (1984). Wetlands of the United States: Current Status and Trends. Washington, D.C., the USA, Fish and Wildlife Service, 59 pp.

Turner, R.K., Morse-Jones, S., \& Fisher, B. (2010). Ecosystem valuation: A sequential decision support system and quality assessment issue. Annals of the York Academy of Scence, 1185(1), 79-101. https://doi.org/10.1111/j.1749-6632.2009.05280.x

Turner, R.K., van den Bergh, J.C.J.M., Söderqvist, T., Barendregt, A., van der Straaten, J., Maltby, E., \& van Ierland, E.C. (2000). Special issue: The values of wetlands: Landscape and institutional perspectives. Ecological-economic analysis of wetlands: Scientific integration for management and policy. Ecological Economics, 35, 7-23. https:// doi.org/10.1016/S0921-8009(00)00164-6

Turpie J., \& Joubert A. (2001). Estimating potential impacts of a change in river quality on the tourism value of Kruger National Park: An application of travel cost, contingent and conjoint valuation methods. Water SA, 27(3), 387-398. https://doi.org/10.4314/wsa.v27i3.4983

Turpie, J.K., Lannas, K., Scovronick, N., \& Louw, A. (2010), Wetland Valuation. Vol I: Wetland Ecosystem Services And Their Valuation: A Review Of Current Understanding And Practice (WRC Report No. TT 440/09). Limpopo, South Africa, Water Research Commission, 115 pp.

Van Zyl, H., \& Leiman, A. (2002). Hedonic approaches to estimating the impacts of open spaces: A case study in the Cape. South African Journal of Economics and Management, 5(2), 379-394. https://doi.org/10.4102/sajems.v5i2.2681 